\title{
Influencia del agua termal sobre las propiedades físicas del concreto, Huancavelica
}

\author{
Tobías Edverson Untiveros Leon, Jhonsver Alfredo Salvatierra De la Cruz, Abdon Dante Olivera Quintanilla, \\ Jorge Luis Ortega Vargas
}

Universidad Nacional de Huancavelica, Avenida Agricultura 319-321, Paturpampa 09001, Huancavelica, Perú

Enviado el 10 de noviembre del 2021. Aceptado el 8 de enero del 2022.

DOI: https://doi.org/10.33017/RevECIPeru2021.0007/

\section{Resumen}

Actualmente uno de los principales problemas que genera el sector de construcción se produce por uso desmesurado del agua potable convirtiendo al agua termal en una alternativa sostenible para mitigar el impacto o daño ambiental y potenciar su uso en la industria de la construcción. En el presente trabajo de investigación tiene como objetivo determinar la influencia del agua termal sobre las propiedades físicas del concreto, buscando reemplazar el agua potable de la mezcla de concreto con el agua termal de la piscina San Cristóbal en la ciudad de Huancavelica. Se realiza estudios físicos y químicos al agua para ser usada en la elaboración de concreto. El diseño de mezcla para resistencias de: f'c $=210 \mathrm{~kg} / \mathrm{cm} 2$, según el método $\mathrm{ACl} 211$; para ello utilizamos agregado grueso de cantera Ocopa (Lircay), fino de cantera Orcotuna (Huancayo), cemento Andino Extraforte, agua termal con diferentes concentraciones de $25 \%, 50 \%, 75 \%, 100 \%$ y agua potable como control positivo, se elaboró 60 probetas de concreto de 6 por 12 pulgadas. Se estudia el comportamiento del concreto en estado fresco y endurecido a edades de 7, 14 y 28 días, respecto al primero se determinó el asentamiento, peso unitario y al estado endurecido la resistencia a compresión, peso unitario. La presencia de agua termal en el concreto fresco en porcentajes de $25 \%, 50 \%, 75 \%, 100 \%$ aumenta la consistencia de la mezcla (asentamiento) en 3.3 pulg, 3.4 pulg, 3.6 pulg, 3.7 pulg respectivamente ; en estado endurecido, la resistencia a compresión a 28 días al aumentar porcentajes de $25 \%, 50 \%, 75 \%, 100 \%$ de agua termales es de $217 \mathrm{~kg} / \mathrm{cm} 2$, $212.53 \mathrm{~kg} / \mathrm{cm} 2,208 \mathrm{~kg} / \mathrm{cm} 2$ y $203 \mathrm{~kg} / \mathrm{cm} 2$ respectivamente y los pesos unitarios permanecen sin cambios significativos. Se concluye que es factible el uso del agua termal en la preparación del concreto puesto que cumple con los requisitos mínimos que señala la Norma Técnica Peruana, especialmente el $25 \%$ de agua termal a 14 días incrementa la resistencia en más de $10 \%$ de resistencia esperada; siendo en todos los casos aptos para su utilización según la norma, lo que produciría un impacto positivo, reduciendo el uso de agua potable y llegar a ser empleada en contexto local Huancavelicano.

Descriptores: concreto, agua termal, construcción, sostenible, resistencia, asentamiento, peso unitario

\section{Abstract}

Currently one of the main problems generated by the construction sector is caused by excessive use of drinking water, making thermal water a sustainable alternative to mitigate environmental impact or damage and enhance its use in the construction industry. The objective of this research work is to determine the influence of thermal water on the physical properties of concrete, seeking to replace the drinking water of the concrete mixture with the thermal water of the San Cristóbal pool in the city of Huancavelica. Physical and chemical studies are carried out on water to be used in the manufacture of concrete. The mixture design for resistances of: $f^{\prime} \mathrm{C}=210 \mathrm{~kg} / \mathrm{cm} 2$, according to the ACl 211 method; For this we use coarse aggregate from Ocopa quarry (Lircay), fine from Orcotuna quarry (Huancayo), Andean Extraforte cement, thermal water with different concentrations of $25 \%, 50 \%, 75 \%, 100 \%$ and 
drinking water as a positive control. 60 6-by-12-inch concrete specimens. The behavior of concrete in the fresh and hardened state is studied at ages of 7, 14 and 28 days, with respect to the first, the settlement, unit weight and the hardened state the compressive strength, unit weight were determined. The presence of thermal water in fresh concrete in percentages of $25 \%, 50 \%, 75 \%, 100 \%$ increases the consistency of the mix (slump) by 3.3 in, 3.4 in, 3.6 in, 3.7 in respectively; In the hardened state, the compressive strength at 28 days when increasing percentages of $25 \%, 50 \%, 75 \%, 100 \%$ of thermal water is $217 \mathrm{~kg} / \mathrm{cm} 2,212.53 \mathrm{~kg} / \mathrm{cm} 2,208 \mathrm{~kg} / \mathrm{cm} 2$ and $203 \mathrm{~kg} / \mathrm{cm} 2$ respectively and the unit weights remain without significant changes. It is concluded that the use of thermal water in the preparation of concrete is feasible since it meets the minimum requirements established by the Peruvian Technical Standard, especially $25 \%$ of thermal water after 14 days increases the resistance by more than $10 \%$ of the expected resistance; being in all cases suitable for use according to the norm, which would produce a positive impact, reducing the use of drinking water and becoming used in the local Huancavelicano context.

Keywords: concrete, thermal water, construction, sustainable, strength, settlement, unit weight

\section{Introducción}

El concreto es uno de los materiales de más uso en la construcción a nivel mundial, nacional y regional, uno de los componentes más importantes es el agua donde es indispensable en el proceso de construcción, el agua potable es un insumo muy escaso en los últimos años siendo necesario su mejor uso y aprovechamiento racional, por esta razón buscamos nuevas alternativas como el uso de aguas termales enfocados en la construcción. Actualmente, una de cada cinco personas (20\%) de la población mundial no tiene acceso al agua potable en el mundo, y se prevé que para el 2025 dos tercios de la población mundial, o sea $66.6 \%$, enfrentará problemas de escasez del agua, y un tercio de la población global (33.3\%) vivirán en escasez absoluta del agua [1]. Latinoamérica a pesar de contar con la tercera parte de las fuentes de agua dulce en el mundo, será una de las regiones más afectadas por el cambio climático. La escasez del agua en el Perú se da principalmente en las zonas con menos recursos económicos, motivo por el cual muchos peruanos compran agua a camiones cisternas, exponiéndose a diferentes enfermedades. Además, el uso de este importante líquido está racionalizado, de modo que algunas familias cuentan con agua potable solo por algunas horas [2] .

Se consideran aguas termales a aquellas que surgen del interior de la Tierra cuya temperatura es superior a los $20^{\circ} \mathrm{C}$ o aguas con temperaturas superiores en 5 o $6^{\circ} \mathrm{C}$ a la temperatura ambiental de la zona de surgencia [3]. De que estas aguas provienen de capas subterráneas que se hallan a mayor temperatura, las cuales son ricas en diferentes componentes minerales [4]. El recurso termal en el país se encuentra ampliamente distribuido. Prácticamente contamos con fuentes en todas las regiones del país, con excepción de la selva baja y algunas zonas costeras. Casi en la totalidad de las fuentes termales se encuentran ubicadas sobre los $2000 \mathrm{msnm}$ en la cordillera andina, sólo 17 de más de 500 fuentes inventariadas a nivel nacional [3].

Que es factible el uso del agua termal en la preparación del concreto puesto que cumple con los requisitos mínimos que señala la norma además la norma señala que se puede utilizar aguas no potables en el uso del concreto cuya reducción en la resistencia del concreto no sea mayor al $10 \%$ [5]. El concreto con agua subterránea tuvo mejor resistencia donde se obtuvo un $113.34 \%$ de la resistencia requerida, también podemos concluir que nuestras mezclas de concreto eran de consistencia normal y de buena manejabilidad, obteniendo resultados de asentamiento muy cercanos al asentamiento de diseño que fue de 3"4 ", lo que quiere decir que la mezcla tiene una cantidad de agua óptima sin necesidad de un tratamiento previo [6].

La finalidad del tema de investigación es formar conocimiento a partir de circunstancias propias de la zona por tal razón el objetivo es determinar la influencia del agua termal de $25 \%, 50 \%, 75 \%$ y $100 \%$ sobre las propiedades físicas del concreto buscando nuevas alternativas sostenibles de reemplazar el agua potable de la mezcla de concreto con agua termal [7].

\section{Metodología}

\subsection{Tipo de investigación}

\section{- Cuantitativo}




\subsection{Nivel de investigación}

- Explicativo

\subsection{Diseño de investigación}

Experimental. - Su característica principal consiste en la manipulación, control y aleatorización de las variables, ya que se realizó ensayos de laboratorio para obtener resultados de un grupo experimental y un grupo de control.

\subsection{Variables:}

- Independiente: agua termal.

- Dependiente: asentamiento, peso unitario en concreto fresco, peso unitario en concreto endurecido, resistencia a compresión.

\subsection{Población}

La población para el presente proyecto estará constituida por probetas de 6" x 12 " $(15 \mathrm{~cm}$ de diámetro $\times 30 \mathrm{~cm}$ de altura). Especímenes cilíndricas estándares de concreto para resistencia de f'c $=210 \mathrm{~kg} / \mathrm{cm} 2$, elaborado con agua termal de $25 \%, 50 \%, 75 \%$ y $100 \%$ y agua potable como control.

\subsection{Muestra}

El número de muestras serán 60 probetas de 6 " $\mathrm{x}$ 12" pulgadas especímenes cilíndricas estándares de concreto para resistencia de f'c $=210 \mathrm{~kg} / \mathrm{cm} 2$, hay cuatro diseños para cada diseño se hicieron 12 probetas, elaborados y conformados con diferentes porcentajes de agua termal de $25 \%, 50 \%, 75 \%$ y $100 \%$, y como control positivo se han elaborado 12 probetas con $100 \%$ agua potable, fueron etiquetados con las siglas AP (agua potable) y AT (agua termal), a los cuales se le asignó una numeración “1, 2, 3, 4, 5, 6, 7, 8, 9, 10, 11, 12", se presenta la tabla 1 para mayor comprensión.

Tabla 1. Registro o cantidad de probetas

\begin{tabular}{|c|c|c|c|}
\hline \multirow{2}{*}{ Tipo de mezcla } & \multicolumn{3}{|c|}{ Edad de los especímenes (días) } \\
\cline { 2 - 4 } & $\mathbf{7}$ & $\mathbf{1 4}$ & $\mathbf{2 8}$ \\
\hline Agua Potable 100\% & 4 & 4 & 4 \\
\hline AT 25\%\% + AP 75\% & 4 & 4 & 4 \\
\hline AT 50\% + AP 50\% & 4 & 4 & 4 \\
\hline AT 75\% + AP 25\% & 4 & 4 & 4 \\
\hline Agua Termal 100\% & 4 & 4 & 4 \\
\hline Subtotal & 20 & 20 & 20 \\
\hline Total & \multicolumn{3}{|c}{60 (sesenta) } \\
\hline
\end{tabular}

\subsection{Conceptos básicos y definición de términos}

\subsubsection{Concreto}

Se dice que concreto es una mezcla adecuadamente dosificada de cemento, agua, agregados finos y gruesos, las propiedades del concreto están determinadas principalmente por las características físicos y químicas de los materiales que lo componen, hay dos estados del concreto el fresco y endurecido [8].

\subsubsection{Cemento}

Es el elemento que tiene la propiedad de fraguar y endurecer con la presencia del agua, porque la reacción es químicamente con ella para formar un material de buenas propiedades aglutinantes [9].

\subsubsection{Agua}

Es el elemento que hidrata las partículas de cemento y hace que estas desarrollen sus propiedades aglutinantes, es indispensable para la elaboración de concretos ya que de este elemento depende su hidratación, es importante conocer las características físicas y químicas del tipo de agua que se va a emplear [8].

\subsubsection{Agregados}

Los agregados son materiales inertes que tienen una resistencia propia suficiente que no perturban ni afectan en el proceso de endurecimiento del cemento, garantizan una adherencia con la pasta de cemento endurecida, dentro de los agregados encontramos dos clasificaciones, los agregados gruesos o gravas y los agregados finos o arenas a los que realizó sus respectivos análisis [8].

\subsubsection{Análisis granulométrico}

El análisis granulométrico es el proceso de dividir una muestra de agregado en partes de igual tamaño de partículas. Su propósito es determinar la distribución por tamaño del agregado.

\subsubsection{Recolección de datos}

Lugar y ubicación del desarrollo de la investigación en el barrio San Cristóbal, distrito, provincia y departamento de Huancavelica, con impacto en la misma Ciudad de Huancavelica en la manipulación, control y aleatorización de las variables de la 
investigación se realizó dentro de las instalaciones la Universidad Nacional de Huancavelica, el espacio temporal se dio entre los meses de febrero a octubre del año 2021. Utilizando como instrumentos: ficha de registros de, hojas de cálculo digitales para el procesamiento de datos y cámara fotográfica durante el proceso de investigación.

\subsection{Procesamiento y Obtención de datos}

Cemento: Se utiliza el tipo de cemento Andino Forte para construcción de obras en general, producido por la empresa UNACEM bajo los parámetros establecidos en la norma NTP 334.009 [10].

Agregado fino y agregado grueso: Su definición y clasificación de agregados para uso en morteros y concretos bajo la norma NTP 400.011 [11], los agregados grueso y fino proceden de cantera Ocopa (Lircay), de cantera Orcotuna (Huancayo), respectivamente, bajo los parámetros establecidos en la norma NTP 400.037 [12], para extracción y preparación de las muestras la norma NTP 400.010.

Toma de muestra de agua: El agua utilizada para la elaboración de concreto de control es agua potable de la red suministrado por la empresa Emapa Huancavelica S.A.C y agua termal se extrajo de la piscina San Cristóbal en las coordenadas UTM DATUM WGS 84 - Zona 18S: 50²8'10.33" E; 8586'833.24" N, Cota: 3660 msnm, la extracción se realizó el 12 de febrero de 2021 en condiciones climáticas adecuadas. Bajo los parámetros establecidos en la norma NTP 339.070 [13].

Análisis físico-químico del agua: $\mathrm{La}$ caracterización del agua se realizó en laboratorio PACIFIC CONTROL CMA (certificada por INACAL) en Lima, Perú donde fueron transportadas, protegidas y refrigerada de manera adecuada en frascos que el mismo laboratorio nos proporcionó bajo los parámetros estipulados en la Norma Técnica Peruana 339.088 [14].

Análisis granulométrico del agregado fino, grueso y global: El ensayo consistió en separar a través de una serie de tamices, una muestra seca de agregado fino y grueso con una masa conocida donde los tamices van progresivamente de una abertura mayor a menor para determinar la distribución de del tamaño de partículas, teniendo en cuenta el protocolo que estipula en el laboratorio de la universidad, se pesa una cantidad representativa de los agregados; para el agregado fino una cantidad mínima de $\mathbf{3 0 0}$ gramos y para el agregado grueso unos 5000 gramos como mínimo según la NTP 400.012 [15] y ASTM C33, para determinar el porcentaje de los pesos retenidos en cada tamiz.

Peso específico y absorción de agregados gruesos: El ensayo consistió en determina la relación con temperatura constante de la masa en el aire de un volumen unitario de material permeable tiene que estar incluyendo los poros permeables e impermeables que son naturales del material respecto de la masa en el aire de la misma densidad de un volumen igual de agua termal libre de gases bajo los parámetros de la Norma NTP 400.021 y ASTM C 127.

\section{Gravedad específica y absorción de agregados}

finos: El procedimiento para determinar el porcentaje total de humedad evaporable en una muestra de agregado fino o grueso por secado. La humedad evaporable incluye la humedad superficial y la contenida en los poros del agregado, pero no considera el agua que se combina químicamente con los minerales de algunos agregados y que no es susceptible evaporación, por lo que no está incluida en el porcentaje determinado por este método bajo los parámetros de la Norma NTP 400.022 [16] y ASTM C128

Diseño de mezcla de concreto: Se realiza en laboratorio de tecnología de concreto de la Universidad Nacional de Huancavelica teniendo en cuenta los parámetros y las especificaciones estipulados en la Norma ACI 211 [17]. Teniendo en cuenta información y parámetros básicos para el diseño que son:

- El cemento: el tipo y su densidad.

- Los agregados: análisis granulométrico, módulo de fineza, tamaño máximo nominal, gravedad específica, porcentaje de absorción, peso unitario suelto y compacto, su porcentaje de humedad.

- El agua: su procedencia, condición y algunos análisis en caso sea necesario.

- El porcentaje de aire: según el tamaño máximo y asentamiento requerido.

- Características geométricas, diseño de los elementos a construir, definir la consistencia adecuada (Asentamiento o Slump) y el tamaño máximo nominal del agregado grueso.

- Resistencia especificada del cálculo, f'c (teórico). 
- El grado de control en campo, definido por la desviación estándar $(\sigma)$ y el coeficiente de variación (v).

Probetas de concreto: Se utiliza probetas ó briqueteras de 6" x 12" (150 mm de diámetro x 300 $\mathrm{mm}$ de altura). Las probetas y la elaboración de especímenes de concreto cumplen la norma NTP 339.033 [18].

Toma de muestras del concreto en estado fresco: Se toma las muestras de concreto fresco sobre el cual se realizó las pruebas de peso unitario , asentamiento con el cono de Abrams donde deberán ser representativas de la tanda y se tomó de acuerdo con lo indicado en la NTP 339.036 [19].

\section{Elaboración y curado de especímenes de} concreto en laboratorio: Luego de ser fabricadas las muestras cilíndricas utilizadas para las pruebas de caracterización, se mantiene en su respectivo molde durante las primeras 24 horas \pm 8 horas después del vaciado; luego de ello se desmolda y se introduce en una cámara de curado, las muestras deben ser sumergidas en agua en un tanque de almacenamiento de acuerdo a los requisitos de la NTP 334.077 [20] a temperatura de $23 \pm 2{ }^{\circ} \mathrm{C}$, todo está descrito en la norma NTP 339.183.

Ensayo de la resistencia a compresión del concreto: Los ensayos de compresión a los cilindros de concreto de $210 \mathrm{~kg} / \mathrm{cm} 2$ se realiza a las edades de 7, 14 y 28 días por medio de una máquina de compresión la prensa digital ELE INTERNATIONAL modelo 36-0718/06 capacidad $500.000 \mathrm{lbf}(2.224 \mathrm{kN})$, en las instalaciones del laboratorio de tecnología de concreto de la Universidad Nacional de Huancavelica apoyándonos bajo los parámetros estipulados en la Norma Técnica Peruana NTP 339.034 [21] y la Norma Técnica ASTM C39, con lo que determina la resistencia máxima adquirida de los bloques de concreto en los tiempos de rotura establecidos.

Ecuaciones Utilizadas:

$$
F^{\prime} C=\frac{\mathrm{P}}{\mathrm{A}}
$$

F'c: resistencia

P: Fuerza aplicada

A: Área

La resistencia a la compresión del concreto de acuerdo a la norma E.060 Concreto Armado, si se usa agua no potable, las probetas ensayadas a compresión deben tener resistencia de por lo menos el $90 \%$ de similares con agua potable.

Peso unitario del concreto: Es el método de ensayo normalizado para determinar la masa por unidad de volumen o densidad ("Peso Unitario") y los vacíos en los agregados. Se coloca el concreto en el recipiente de medición en tres capas de aproximadamente igual volumen. Donde se apisona cada capa con 25 golpes con la barra compactadora cuando después de que cada capa ha sido apisonada golpee los lados del recipiente con un mazo 12 veces, usando la fuerza adecuada para cerrar los huecos causados por la varilla perforada y elimine las grandes burbujas de aire atrapado según la norma NTP 339.046 [22] o Norma NTP 400.017, que fue tomada en su totalidad de la norma ASTM C29.

Ecuaciones Utilizadas:

$$
\delta=\frac{W}{V}
$$

$\delta$ : Densidad del hormigón $\left(\mathrm{gr} / \mathrm{cm}^{\wedge} 3\right)$

W: Masa de la probeta (gr)

V: Volumen de la probeta $\left(\mathrm{cm}^{\wedge} 3\right)$

Asentamiento del concreto: Ensayo de revenimiento o asentamiento en el cono de Abrams, de dicho ensayo se comprobó consistencia o fluidez del concreto depende de la cantidad de agua de mezclado según la Norma NTP 339.035 [23] y ASTM C143, se ha encontrado una relación directa entre la cantidad del agua y el asentamiento de una mezcla de concreto. Utilizamos molde de metal con forma cono abierto en sus extremos el diámetro de base inferior 8 pulgadas $(20 \mathrm{~cm})$ y parte superior de 4 pulgadas $(10 \mathrm{~cm})$ formando un ángulo recto con el eje del cono, la altura del molde es 12 pulgadas (30 $\mathrm{cm})$.

Trabajo de gabinete: Se hace con el programa Microsoft Office 2016 (Excel 2016) para comparar y analizar las variables en los especímenes de concreto elaborados con agua potable y agua termal, utilizando este último como insumo alternativo en función de sus parámetros físicos y químicos.

\section{Resultados y Discusión de resultados}

\subsection{Resultados de las propiedades físicas y químicas del agua termal.}


Se realiza estudios físicos y químicos Para determinar sus características al agua como: cloruros, sulfatos, sales de magnesio, sales solubles, $\mathrm{pH}$, sólidos en suspensión (residuo insoluble), materia orgánica, alcalinidad, se obtuvieron los siguientes resultados, los mismos que serán comparados con los parámetros establecidos por la NTP. 339.088.

Tabla 2. Resultados de las características físicas y químicas del agua termal y los límites máximos tolerables.

\begin{tabular}{|l|c|c|}
\hline Descripción & $\begin{array}{c}\text { Limite } \\
\text { Permisible }\end{array}$ & Resultado \\
\hline $\begin{array}{l}\text { Sólidos en } \\
\text { suspensión }\end{array}$ & $5000 \mathrm{ppm}$ max & 5 \\
\hline Materia orgánica & $3 \mathrm{ppm} \mathrm{max}$ & $<0.5$ \\
\hline Alcalinidad & $1000 \mathrm{ppm}$ max & 555 \\
\hline Sulfato & $600 \mathrm{ppm}$ max & 281 \\
\hline Cloruro & $1000 \mathrm{ppm}$ max & 22 \\
\hline PH & $5 \mathrm{a} 8$ & 6.59 \\
\hline Turbidez & $\mathrm{unt}$ & 4.02 \\
\hline Bicarbonatos & $\mathrm{mg} / \mathrm{L}$ & 555 \\
\hline Azufre & $\mathrm{mg} / \mathrm{L}$ & $<0.002$ \\
\hline Calcio & $\mathrm{mg} \mathrm{Fe} / \mathrm{L}$ & 304.4 \\
\hline Magnesio & $\mathrm{mg} \mathrm{Mg} / \mathrm{L}$ & 28 \\
\hline
\end{tabular}

\section{Interpretación:}

Observamos los resultados realizados a una muestra superficial de agua termal del barrio San Cristóbal, donde se aprecia que la cantidad de elementos dañinos para el concreto que este contiene se encuentran dentro de los límites máximos permitidos, todos los parámetros obtenidos en el agua termal se encuentran dentro del rango permisible para el uso en el mezclado del concreto según el MTC y la Norma Técnica Peruana.

\section{Granulometría}

Los resultados del análisis granulométrico se muestran en la figura 1 y 2 , bajo la norma NTP 400.037, se puede apreciar que tiene una buena distribución de sus partículas, es decir, es una arena bien graduada, puesto que se encuentra en su totalidad dentro de los límites granulométricos dispuestos.

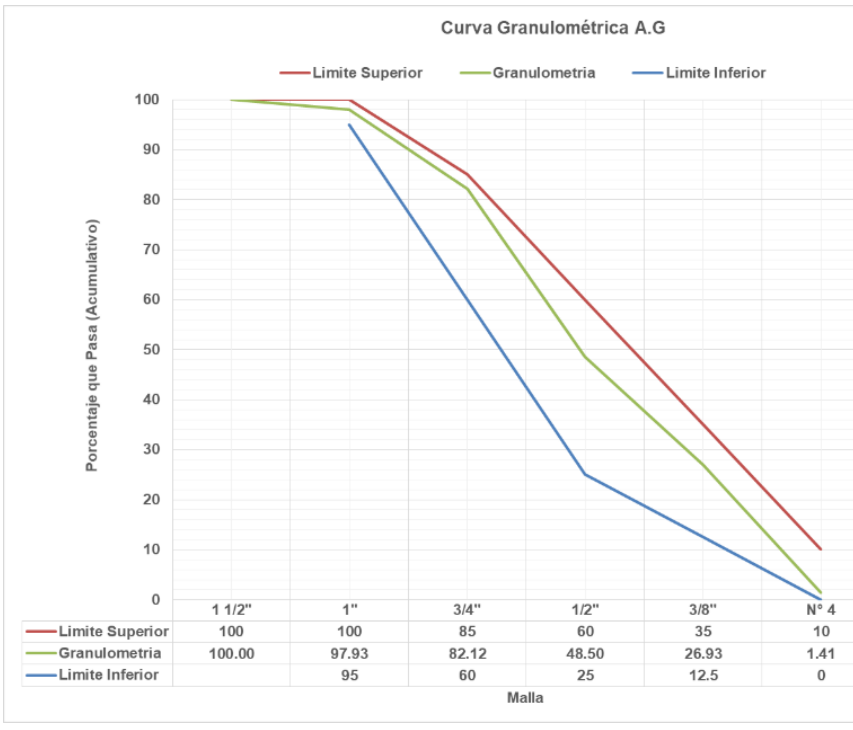

Figura 1. Curva granulométrica del agregado grueso

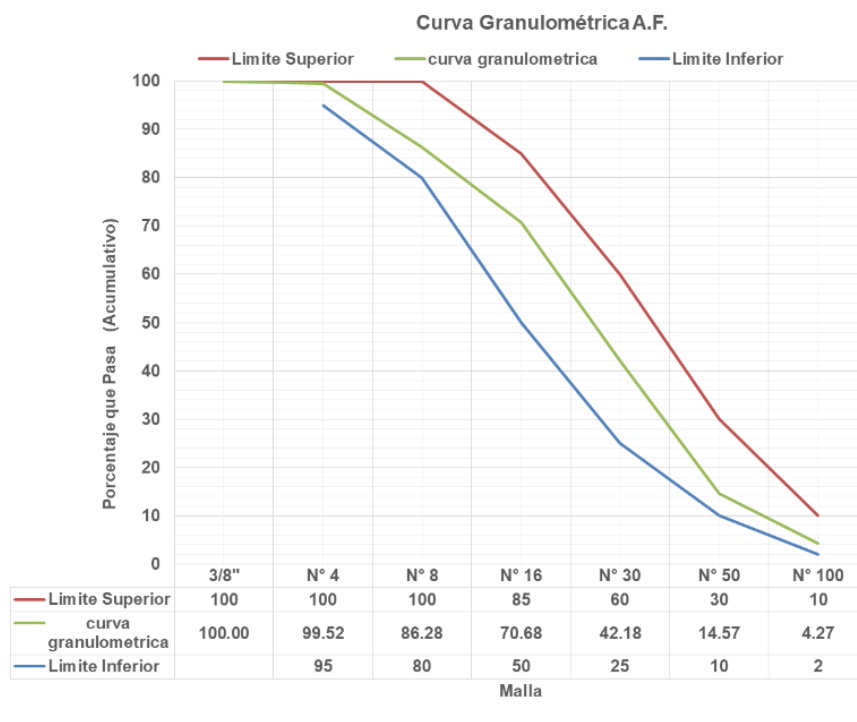

Figura 2. Curva granulométrica del agregado fino

\section{Interpretación:}

Los ensayos de granulometría de los agregados de la cantera donde se extrajo los agregados están dentro de los límites establecidos estos cumplen con los husos granulométricos, por tanto, los tamaños máximos y nominales son confiables.

\subsection{Diseño de mezcla de concreto}

Primeramente, se realiza la caracterización de los agregados, agregado grueso de cantera Ocopa (Lircay) y agregado fino de cantera Orcotuna (Huancayo), en el laboratorio de mecánica de suelos de la Universidad Nacional de Huancavelica. 
Tabla 3: Características físicas de los agregados.

\begin{tabular}{|l|l|l|l|}
\hline \multicolumn{4}{|c|}{ Características físicas de los agregados } \\
\hline $\begin{array}{l}\text { Propiedad } \\
\text { física }\end{array}$ & $\begin{array}{l}\text { Agregado } \\
\text { grueso }\end{array}$ & $\begin{array}{l}\text { Agregado } \\
\text { fino }\end{array}$ & unidad \\
\hline Procedencia & Orcotuna & Ocopa & \\
\hline $\begin{array}{l}\text { tamaño } \\
\text { máximo }\end{array}$ & $11 / 2^{\prime \prime}$ & $3 / 8^{\prime \prime}$ & pulgada \\
\hline $\begin{array}{l}\text { tamaño } \\
\text { máximo } \\
\text { nominal }\end{array}$ & $1 "$ & $N^{\circ} 4$ & pulgada \\
\hline $\begin{array}{l}\text { \%humedad } \\
\text { natural }\end{array}$ & 0.00 & 0.00 & $\%$ \\
\hline $\begin{array}{l}\% \\
\text { absorción }\end{array}$ & 1.76 & 2.16 & $\%$ \\
\hline $\begin{array}{l}\text { peso } \\
\text { especifico }\end{array}$ & 2.6 & 2.54 & $\mathrm{gr} / \mathrm{cm} 3$ \\
\hline $\begin{array}{l}\text { peso unitario } \\
\text { suelto }\end{array}$ & 1383 & 1590 & $\mathrm{~kg} / \mathrm{cm3}$ \\
\hline $\begin{array}{l}\text { peso unitario } \\
\text { varillado }\end{array}$ & 1530 & 1699 & $\mathrm{~kg} / \mathrm{cm} 3$ \\
\hline
\end{tabular}

Tabla 4: Propiedades químicas, físicas y mecánicas del cemento.

\begin{tabular}{|l|c|c|}
\hline Designación & Fórmula & Porcentaje \\
\hline $\begin{array}{l}\text { Silicato } \\
\text { tricálcico }\end{array}$ & 3CaO.SiO2 & $30 \%$ a $50 \%$ \\
\hline $\begin{array}{l}\text { Silicato } \\
\text { dicálcico }\end{array}$ & 2CaO.SiO2 & $15 \%$ a $30 \%$ \\
\hline $\begin{array}{l}\text { Aluminato } \\
\text { tricálcico }\end{array}$ & 3CaO.Al2O3 & $4 \%$ a $12 \%$ \\
\hline $\begin{array}{l}\text { Ferro } \\
\text { aluminato } \\
\text { tetracálcico }\end{array}$ & $\begin{array}{c}4 \text { CaO.Al2O3.Fe2 } \\
\text { O3 }\end{array}$ & $8 \%$ a $13 \%$ \\
\hline $\begin{array}{l}\text { Peso } \\
\text { especifico }\end{array}$ & & 3.12 a 3.15 \\
\hline & & \\
\hline
\end{tabular}

\section{Interpretación:}

Observamos que los agregados cumplen con la norma garantizando así plenamente que sean de alta calidad y que poseen las propiedades mecánicas que le permitan un buen desempeño en la mezcla de concreto.

Tabla 5: Valores promedios de la resistencia a la compresión axial, con diferentes aguas termales a 7días.

\begin{tabular}{|c|c|c|c|c|c|c|c|c|}
\hline$\%$ Agua & Muestra & Diámetro & Edad & $\begin{array}{c}\text { Resistencia de } \\
\text { diseño } \\
(\mathrm{Kg} / \mathrm{cm} 2)\end{array}$ & $\begin{array}{c}\text { Carga } \\
\text { ultima } \\
(\mathrm{Kg})\end{array}$ & $\begin{array}{c}\text { Resistencia } \\
(\mathrm{Kg} / \mathrm{cm} 2)\end{array}$ & $\begin{array}{l}\text { Resistencia } \\
\text { Promedio }\end{array}$ & \% Resistencia \\
\hline \multirow{4}{*}{$\begin{array}{l}100 \% \text { Agua } \\
\text { potable } \\
\text { (Control) }\end{array}$} & 1 & 152.31 & 7 días & 210 & 23500 & 133.00 & \multirow{4}{*}{134.00} & \multirow{4}{*}{$104.69 \%$} \\
\hline & 2 & 152.31 & 7 días & 210 & 24470 & 138.50 & & \\
\hline & 3 & 152.31 & 7 días & 210 & 22970 & 130.00 & & \\
\hline & 4 & 152.31 & 7 días & 210 & 23780 & 134.50 & & \\
\hline \multirow{4}{*}{$\begin{array}{c}100 \% \text { Agua } \\
\text { termal }\end{array}$} & 1 & 152.31 & 7 días & 210 & 18190 & 103.00 & \multirow{4}{*}{98.47} & \multirow{4}{*}{$73.49 \%$} \\
\hline & 2 & 152.31 & 7 días & 210 & 18200 & 103.00 & & \\
\hline & 3 & 152.31 & 7 días & 210 & 15740 & 89.09 & & \\
\hline & 4 & 152.31 & 7 días & 210 & 17460 & 98.80 & & \\
\hline \multirow{4}{*}{$\begin{array}{c}75 \% \text { Agua } \\
\text { termal y } 25 \% \\
\text { agua potable }\end{array}$} & 1 & 152.31 & 7 días & 210 & 17450 & 98.70 & \multirow{4}{*}{100.28} & \multirow{4}{*}{$74.83 \%$} \\
\hline & 2 & 152.31 & 7 días & 210 & 19780 & 111.90 & & \\
\hline & 3 & 152.31 & 7 días & 210 & 18460 & 104.50 & & \\
\hline & 4 & 152.31 & 7 días & 210 & 15150 & 86.00 & & \\
\hline \multirow{4}{*}{$\begin{array}{c}50 \% \text { Agua } \\
\text { termal y } 50 \% \\
\text { agua potable }\end{array}$} & 1 & 152.31 & 7 días & 210 & 19690 & 111.40 & \multirow{4}{*}{113.97} & \multirow{4}{*}{$85.05 \%$} \\
\hline & 2 & 152.31 & 7 días & 210 & 17330 & 98.07 & & \\
\hline & 3 & 152.31 & 7 días & 210 & 15070 & 85.30 & & \\
\hline & 4 & 152.31 & 7 días & 210 & 28470 & 161.10 & & \\
\hline \multirow{4}{*}{$\begin{array}{c}25 \% \text { Agua } \\
\text { termal y } 75 \% \\
\text { agua potable }\end{array}$} & 1 & 152.31 & 7 días & 210 & 21890 & 123.90 & \multirow{4}{*}{137.30} & \multirow{4}{*}{$102.46 \%$} \\
\hline & 2 & 152.31 & 7 días & 210 & 24500 & 138.70 & & \\
\hline & 3 & 152.31 & 7 días & 210 & 25300 & 143.20 & & \\
\hline & 4 & 152.31 & 7 días & 210 & 23340 & 143.40 & & \\
\hline
\end{tabular}


Tabla 6: Valores promedios de la resistencia a la compresión axial, con diferentes aguas termales a 7días.

\begin{tabular}{|c|c|c|c|c|c|c|c|c|}
\hline$\%$ Agua & Muestra & Diámetro & Edad & $\begin{array}{c}\text { Resistencia de } \\
\text { diseño } \\
\text { (Kg/cm2) }\end{array}$ & $\begin{array}{l}\text { Carga } \\
\text { ultima } \\
(\mathrm{Kg})\end{array}$ & $\begin{array}{c}\text { Resistencia } \\
(\mathrm{Kg} / \mathrm{cm} 2)\end{array}$ & $\begin{array}{c}\text { Resistencia } \\
\text { Promedio }\end{array}$ & $\%$ Resistencia \\
\hline \multirow{4}{*}{$\begin{array}{l}100 \% \text { Agua } \\
\text { potable } \\
\text { (Control) }\end{array}$} & 5 & 152.31 & 14 días & 210 & 26840 & 151.90 & \multirow{4}{*}{167.07} & \multirow{4}{*}{$99.44 \%$} \\
\hline & 6 & 152.31 & 14 días & 210 & 27960 & 158.30 & & \\
\hline & 7 & 152.31 & 14 días & 210 & 29740 & 168.30 & & \\
\hline & 8 & 152.31 & 14 días & 210 & 30850 & 174.60 & & \\
\hline \multirow{4}{*}{$\begin{array}{c}100 \% \text { Agua } \\
\text { termal }\end{array}$} & 5 & 152.31 & 14 días & 210 & 26840 & 110.80 & \multirow{4}{*}{119.75} & \multirow{4}{*}{$71.68 \%$} \\
\hline & 6 & 152.31 & 14 días & 210 & 27960 & 136.20 & & \\
\hline & 7 & 152.31 & 14 días & 210 & 29740 & 115.10 & & \\
\hline & 8 & 152.31 & 14 días & 210 & 30850 & 116.90 & & \\
\hline \multirow{4}{*}{$\begin{array}{c}75 \% \text { Agua } \\
\text { termal y } 25 \% \\
\text { agua potable }\end{array}$} & 5 & 152.31 & 14 días & 210 & 24110 & 136.40 & \multirow{4}{*}{137.73} & \multirow{4}{*}{$82.44 \%$} \\
\hline & 6 & 152.31 & 14 días & 210 & 23510 & 133.00 & & \\
\hline & 7 & 152.31 & 14 días & 210 & 21990 & 124.40 & & \\
\hline & 8 & 152.31 & 14 días & 210 & 27760 & 157.10 & & \\
\hline \multirow{4}{*}{$\begin{array}{c}50 \% \text { Agua } \\
\text { termal y } 50 \% \\
\text { agua potable }\end{array}$} & 5 & 152.31 & 14 días & 210 & 24520 & 138.80 & \multirow{4}{*}{154.53} & \multirow{4}{*}{$92.49 \%$} \\
\hline & 6 & 152.31 & 14 días & 210 & 28790 & 162.90 & & \\
\hline & 7 & 152.31 & 14 días & 210 & 27770 & 157.10 & & \\
\hline & 8 & 152.31 & 14 días & 210 & 28150 & 159.30 & & \\
\hline \multirow{4}{*}{$\begin{array}{c}25 \% \text { Agua } \\
\text { termal y } 75 \% \\
\text { agua potable }\end{array}$} & 5 & 152.31 & 14 días & 210 & 34510 & 195.30 & \multirow{4}{*}{190.95} & \multirow{4}{*}{$114.30 \%$} \\
\hline & 6 & 152.31 & 14 días & 210 & 33340 & 188.70 & & \\
\hline & 7 & 152.31 & 14 días & 210 & 36350 & 205.70 & & \\
\hline & 8 & 152.31 & 14 días & 210 & 30770 & 174.10 & & \\
\hline
\end{tabular}

Tabla 7: Valores promedios de la resistencia a la compresión axial, con diferentes aguas termales a 7días.

\begin{tabular}{|c|c|c|c|c|c|c|c|c|}
\hline$\%$ Agua & Muestra & Diámetro & Edad & $\begin{array}{c}\text { Resistencia de } \\
\text { diseño } \\
\text { (Kg/cm2) }\end{array}$ & $\begin{array}{c}\text { Carga } \\
\text { ultima } \\
(\mathrm{Kg})\end{array}$ & $\begin{array}{c}\text { Resistencia } \\
(\mathrm{Kg} / \mathrm{cm} 2)\end{array}$ & $\begin{array}{c}\text { Resistencia } \\
\text { Promedio }\end{array}$ & $\%$ Resistencia \\
\hline \multirow{4}{*}{$\begin{array}{l}100 \% \text { Agua } \\
\text { potable } \\
\text { (Control) }\end{array}$} & 9 & 151.46 & 28 días & 210 & 39380 & 222.80 & \multirow{4}{*}{218.07} & \multirow{4}{*}{$103.84 \%$} \\
\hline & 10 & 151.78 & 28 días & 210 & 37800 & 213.90 & & \\
\hline & 11 & 151.80 & 28 días & 210 & 46380 & 262.40 & & \\
\hline & 12 & 151.39 & 28 días & 210 & 38430 & 217.50 & & \\
\hline \multirow{4}{*}{$\begin{array}{c}100 \% \text { Agua } \\
\text { termal }\end{array}$} & 9 & 157.96 & 28 días & 210 & 34980 & 197.90 & \multirow{4}{*}{203.08} & \multirow{4}{*}{$93.13 \%$} \\
\hline & 10 & 151.24 & 28 días & 210 & 36160 & 204.60 & & \\
\hline & 11 & 151.57 & 28 días & 210 & 35630 & 201.60 & & \\
\hline & 12 & 151.70 & 28 días & 210 & 36800 & 208.20 & & \\
\hline \multirow{4}{*}{$\begin{array}{c}75 \% \text { Agua } \\
\text { termal y } 25 \% \\
\text { agua potable }\end{array}$} & 9 & 151.98 & 28 días & 210 & 35960 & 203.50 & \multirow{4}{*}{208.00} & \multirow{4}{*}{$95.38 \%$} \\
\hline & 10 & 151.91 & 28 días & 210 & 37870 & 214.30 & & \\
\hline & 11 & 151.23 & 28 días & 210 & 35090 & 198.60 & & \\
\hline & 12 & 151.30 & 28 días & 210 & 38110 & 215.60 & & \\
\hline \multirow{6}{*}{$\begin{array}{c}50 \% \text { Agua } \\
\text { termal y } 50 \% \\
\text { agua potable }\end{array}$} & 9 & 151.81 & 28 días & 210 & 39770 & 225.10 & \multirow{4}{*}{212.53} & \multirow{4}{*}{$97.46 \%$} \\
\hline & 10 & 152.31 & 28 días & 210 & 38420 & 217.40 & & \\
\hline & 11 & 152.31 & 28 días & 210 & 33030 & 186.90 & & \\
\hline & 12 & 152.31 & 28 días & 210 & 34480 & 195.10 & & \\
\hline & 9 & 151.90 & 28 días & 210 & 38200 & 216.20 & \multirow{2}{*}{217.00} & \multirow{2}{*}{$99.51 \%$} \\
\hline & 10 & 151.27 & 28 días & 210 & 39060 & 221.00 & & \\
\hline
\end{tabular}




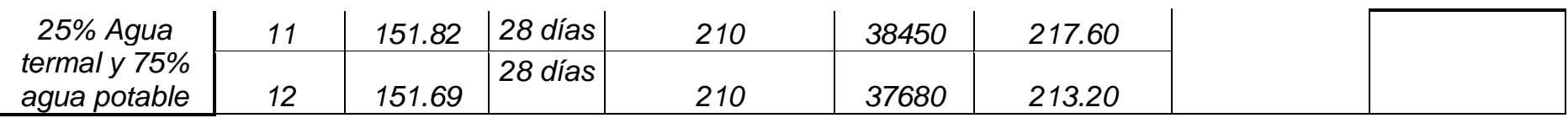

Tabla 8. Dosificación de concretos en volumen por m3 de mezcla

\begin{tabular}{|c|c|c|c|c|c|c|}
\hline \multirow{2}{*}{ Cantidad de materiales } & \multicolumn{6}{|c|}{ Dosificación por tanda de 0.00556 m3 para f'c = 210 kg/cm2 } \\
\cline { 2 - 7 } & AP 100\% & AT 100\% & AT 75\% & AT 50\% & AT 25\% & unidad \\
\hline Cemento & 1.923 & 1.923 & 1.923 & 1.923 & 1.923 & $\mathrm{~kg}$ \\
\hline Agregado grueso & 5.674 & 5.674 & 5.674 & 5.674 & 5.674 & $\mathrm{~kg}$ \\
\hline Agregado fino & 4.067 & 4.067 & 4.067 & 4.067 & 4.067 & $\mathrm{~kg}$ \\
\hline Agua Potable & 2.473 & 0.000 & 0.618 & 1.237 & 1.855 & lts \\
\hline Agua Termal & 0.000 & 2.473 & 1.855 & 1.237 & 0.618 & lts \\
\hline Aire & 1.5 & 1.5 & 1.5 & 1.5 & 1.5 & $\%$ \\
\hline Slump & $3^{\prime \prime}-4 "$ & $3 "-4 "$ & $3^{\prime \prime}-4 "$ & $3 "-4 "$ & $3^{\prime \prime}-4 "$ & - \\
\hline
\end{tabular}

Luego de los ensayos realizados en laboratorio se determina la cantidad de materiales para alcanzar la resistencia $f^{\prime} c=210 \mathrm{~kg} / \mathrm{cm} 2$, se realiza los diseños de mezclas considerando como única variante al agua termal según las propiedades físicas y mecánicas de los mismos, la dosificación es expresado en volumen de $0.00556 \mathrm{~m} 3$ como se muestra en la tabla 8.

\section{Interpretación:}

Se muestran los resultados de diseño de mezcla de concreto obtenidos, expresados en m3 para un concreto $f^{\prime} c=210 \mathrm{~kg} / \mathrm{cm} 2$. Para el concreto patrón, la dosificación de cemento, agua, agregado fino y grueso se halla de acuerdo a las tablas indicadas en el método de diseño de mezclas del ACI 211.1., y para concretos con adiciones de agua termal se utilizó el mismo diseño anterior descrito con la única diferencia que la adición de los porcentajes agua termal en $25 \%, 50 \%, 75 \%$ y $100 \%$, con respecto al agua del concreto patrón, considerando el mismo slump para todas las muestras.

\subsection{Asentamiento y trabajabilidad del concreto fresco}

El asentamiento es una de las propiedades importantes del concreto en estado fresco, ya que se puede conocer el comportamiento del concreto, este ensayo se hice para todas las muestras, en el siguiente gráfico se muestran los valores obtenidos del asentamiento para las concentraciones de agua termal en relación al asentamiento del agua potable.

Tabla 9: Resultado de Asentamiento y trabajabilidad del concreto de todas las muestras.

\begin{tabular}{|l|l|}
\hline Asentamiento promedio & pulgada \\
\hline Potable $100 \%$ & 3.1 \\
\hline Termal $25 \%$ + Potable $75 \%$ & 3.3 \\
\hline Termal $50 \%$ + Potable $50 \%$ & 3.4 \\
\hline Termal $75 \%$ + Potable $25 \%$ & 3.6 \\
\hline Termal $100^{\circ} \%$ & 3.7 \\
\hline
\end{tabular}

\section{Asentamiento vs porcentage de} agua

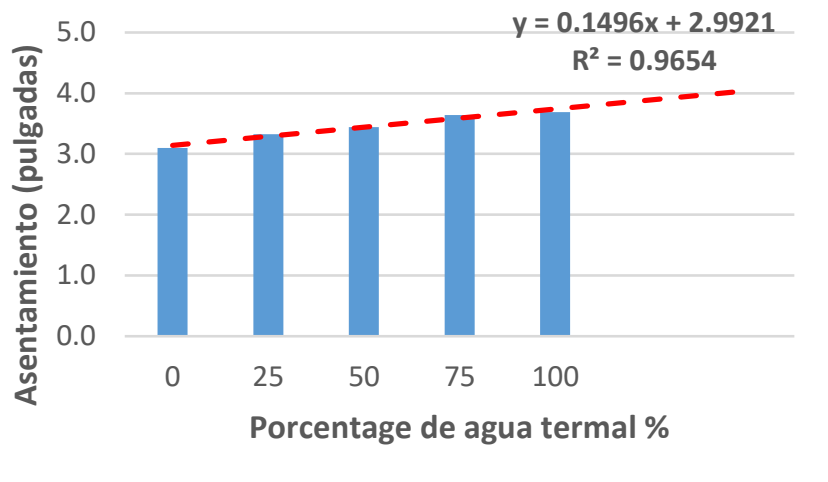

Figura 3. Asentamiento del concreto

\section{Interpretación:}

El valor de referencia es el agua potable que da un asentamiento de 3.1pulg; para el agua termal 25\%, $50 \%, 75 \%$, 100\% está en 3.3 pulg, 3.4 pulg, 3.6 pulg, 3.7 pulg respectivamente, cabe destacar que a mayor concentración de agua termal el asentamiento aumenta, de estos resultados podemos concluir que nuestras mezclas de concreto eran de consistencia normal y de buena manejabilidad, obteniendo resultados de asentamiento muy cercanos al asentamiento de 
diseño que fue de 3"-4", lo que quiere decir que la mezcla tiene una cantidad de agua óptima, manteniendo siempre entre 3-4" de slump, mediante este ensayo se logra apreciar una clara influencia del agua termal en la mezcla de concreto, en razón de que aumenta la cantidad de agua hasta en un $4.8 \%$.

\subsection{Peso unitario del concreto fresco}

Tabla 10: Resultados de peso unitario del concreto fresco

\begin{tabular}{|c|c|c|}
\hline Peso unitario & fresco & und \\
\hline Potable $100 \%$ & 2147.33 & $\mathrm{~kg} / \mathrm{m} 3$ \\
\hline Termal $25^{\circ} \%+$ Potable $75 \%$ & 2147.34 & $\mathrm{~kg} / \mathrm{m} 3$ \\
\hline Termal $50^{\circ} \%+$ Potable $50 \%$ & 2146.86 & $\mathrm{~kg} / \mathrm{m} 3$ \\
\hline Termal $75^{\circ} \%+$ Potable $25 \%$ & 2146.33 & $\mathrm{~kg} / \mathrm{m} 3$ \\
\hline Termal $100^{\circ} \%$ & 2146.21 & $\mathrm{~kg} / \mathrm{m} 3$ \\
\hline
\end{tabular}

\section{Interpretación:}

El concreto elaborado con agua termal con diferentes dosificaciones se encuentran dentro de los parámetros establecidos por la NTP 339.046 que menciona "Que el peso unitario del concreto en estado fresco debe resultar entre los valores de 1842 a 2483 kg/m3". Lo que demuestra que el concreto elaborado con agua potable y termal no presenta diferencias significativas entre sí.

\subsection{Peso unitario del concreto endurecido}

Tabla 10: Resultados de peso unitario del concreto endurecido de 7, 14 y 28 días.

\begin{tabular}{|c|c|c|c|}
\hline $\begin{array}{c}\text { Densidad } \\
\text { promedio }\end{array}$ & 7 días & 14 días & 28 días \\
\hline $\begin{array}{c}\text { Agua Potable } \\
100 \%\end{array}$ & 2325.73 & 2335.16 & 2322.89 \\
\hline $\begin{array}{c}\text { Agua Termal } \\
100 \%\end{array}$ & 2339.18 & 2345.03 & 2313.91 \\
\hline $\begin{array}{c}\text { AT } 75^{\circ} \%+\text { AP } \\
25 \%\end{array}$ & 2327.90 & 2323.71 & 2347.49 \\
\hline $\begin{array}{c}\text { AT } 50^{\circ} \%+\text { AP } \\
50 \%\end{array}$ & 2329.31 & 2330.51 & 2320.28 \\
\hline $\begin{array}{c}\text { AT } 25^{\circ} \%+\text { AP } \\
75 \%\end{array}$ & 2311.20 & 2330.89 & 2350.08 \\
\hline
\end{tabular}

\section{Interpretación:}

Los valores de peso unitario de concreto endurecido si cumplen con la norma que está dentro del rango no hay variación significativa respecto a dichos parámetros.

\subsection{Resistencia a compresión del concreto patrón o control.}

La norma $\mathrm{ACl} 211$ establece que las muestras de prueba elaborados con agua potable a la edad de 28 días deben alcanzar una resistencia del 100\%.

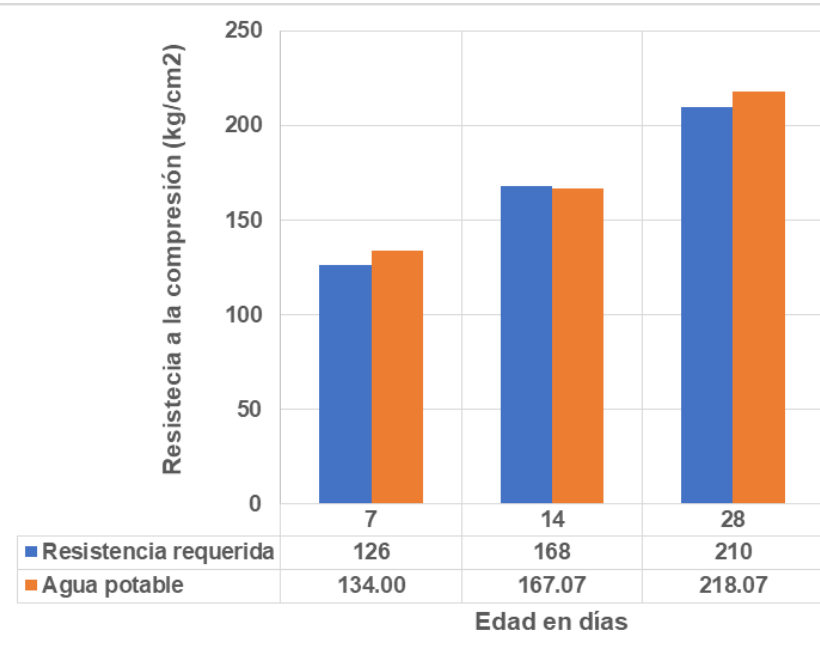

Figura 4.Resistencia promedio de las probetas de concreto con agua potable los días 7, 14 y 28.

Los resultados de resistencia a la compresión simple indican que los especímenes de concreto de control o patrón elaborados con agua potable se encuentran por encima y en rango de las resistencias esperadas según la norma $A C I 211$, ver la figura 4 para comprobar de esta manera que el diseño de mezcla que se utilizó para la investigación está correctamente elaborado.

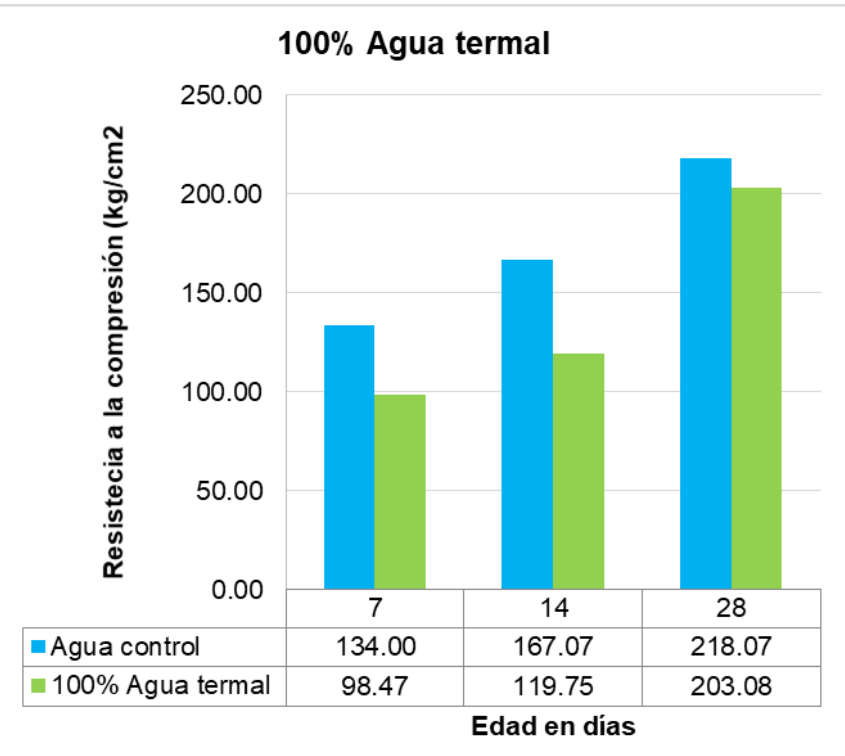


Figura 5. Resistencia promedio de las probetas de concreto con $100 \%$ agua termal los días 7, 14 y 28.

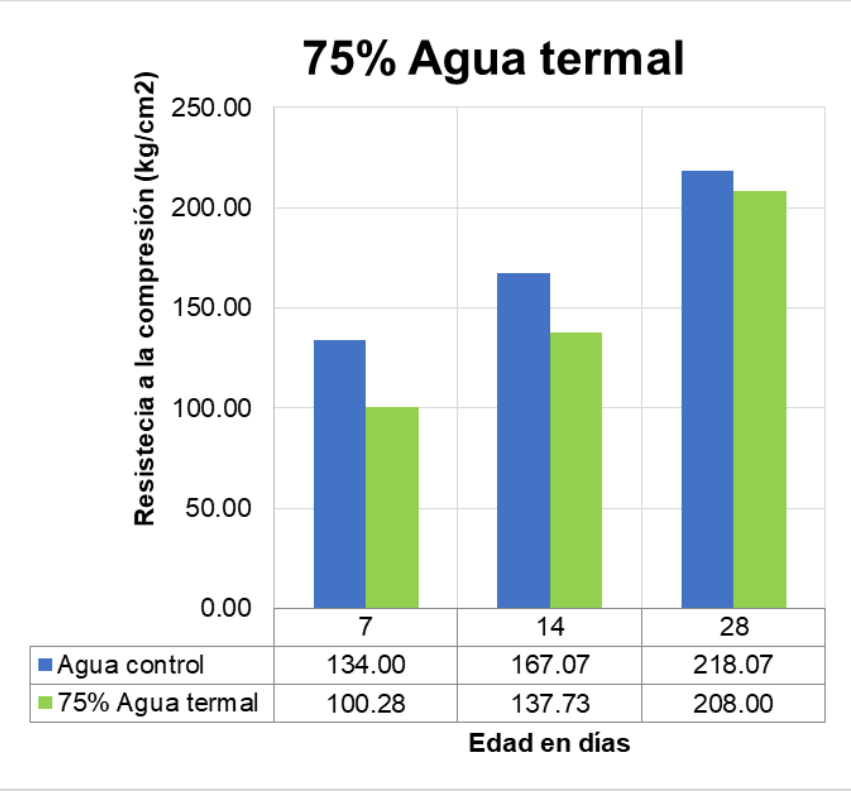

Figura 6. Resistencia promedio de las probetas de concreto con 75\% agua termal los días 7, 14 y 28.

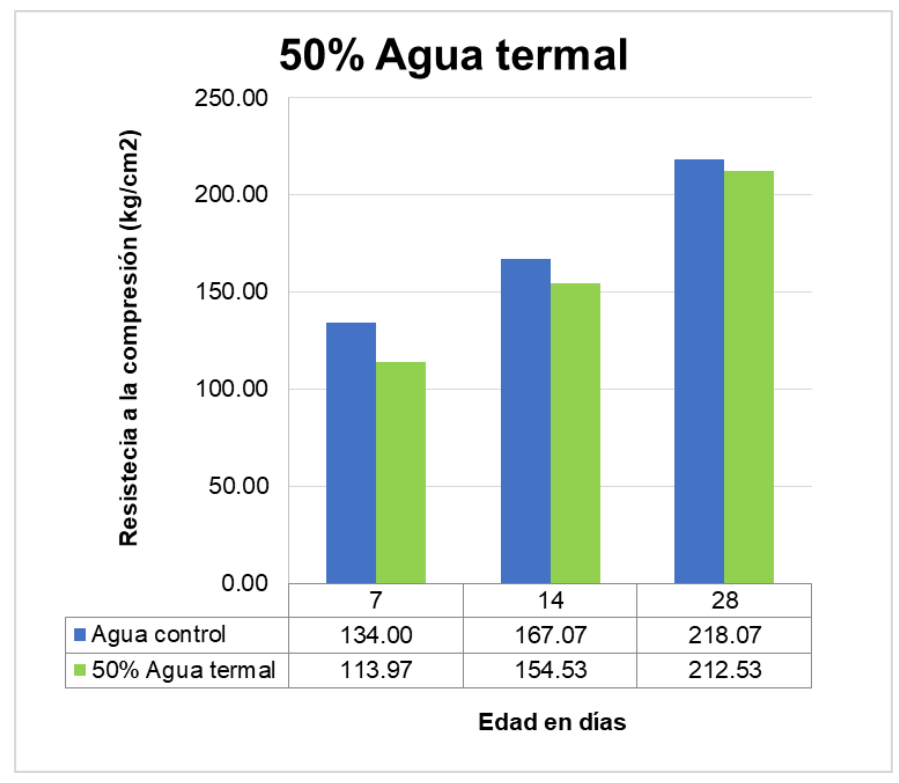

Figura 7. Resistencia promedio de las probetas de concreto con 50\% agua termal los días 7, 14 y 28.

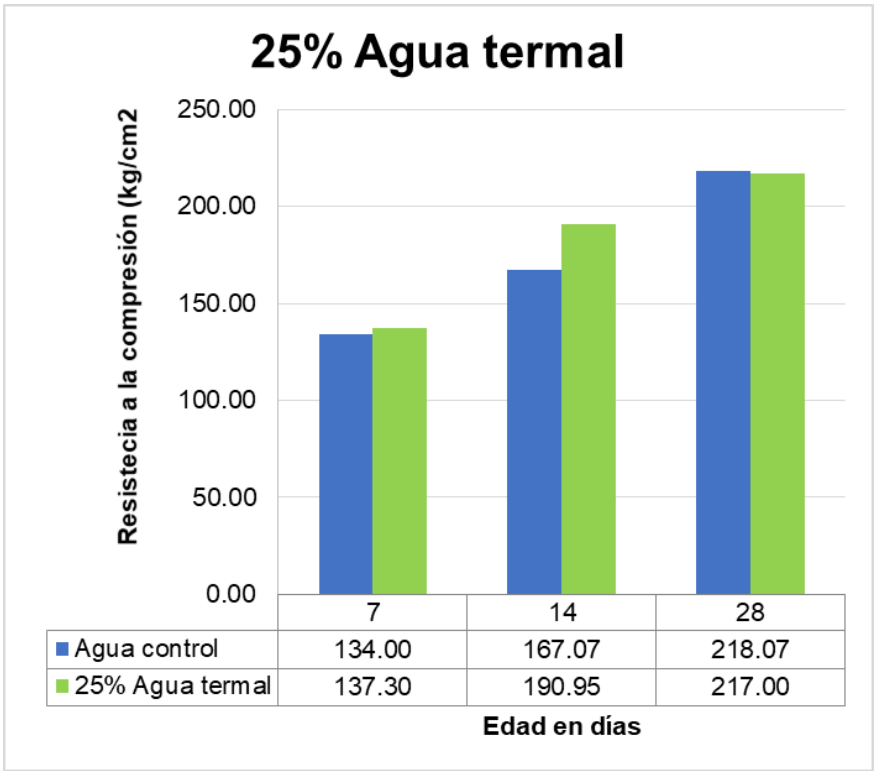

Figura 8. Resistencia promedio de las probetas de concreto con 25\% agua termal los días 7, 14 y 28.

Se muestran los valores promedios de la resistencia a la compresión axial de los testigos de diferentes dosificaciones, a edades de 7,14 y 28 ver en la tabla 5,6 y 7 .

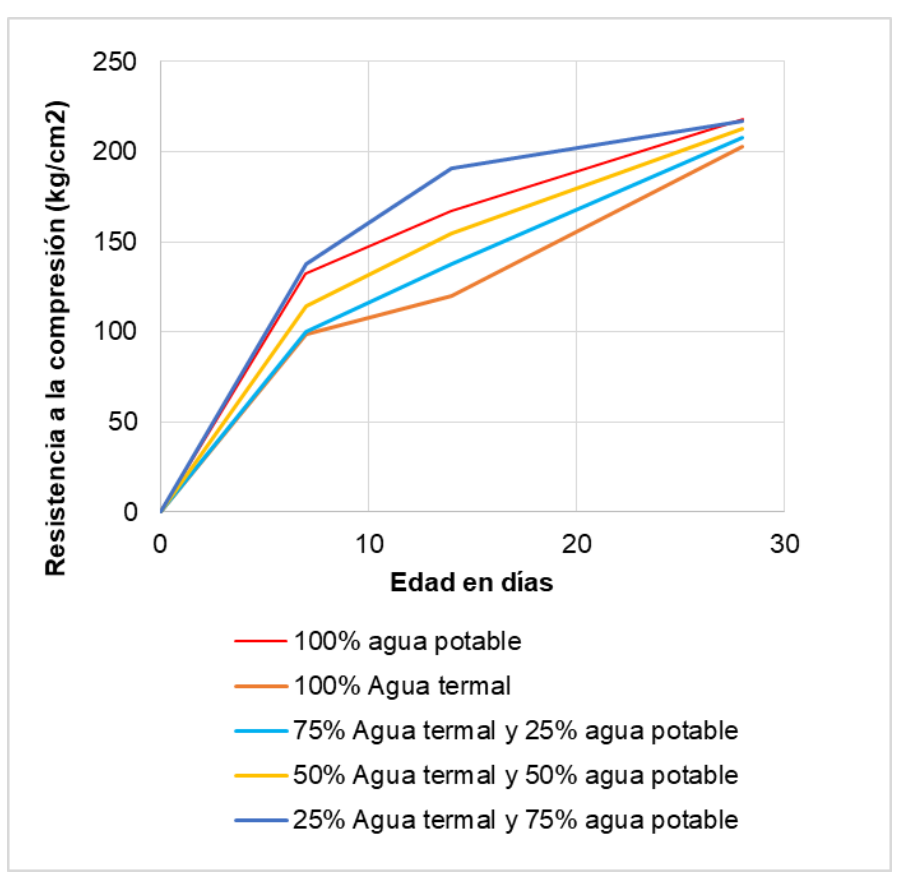

Figura 9. Representación gráfica de la resistencia de todo las dosificaciones para los días 7, 14 y 28. 


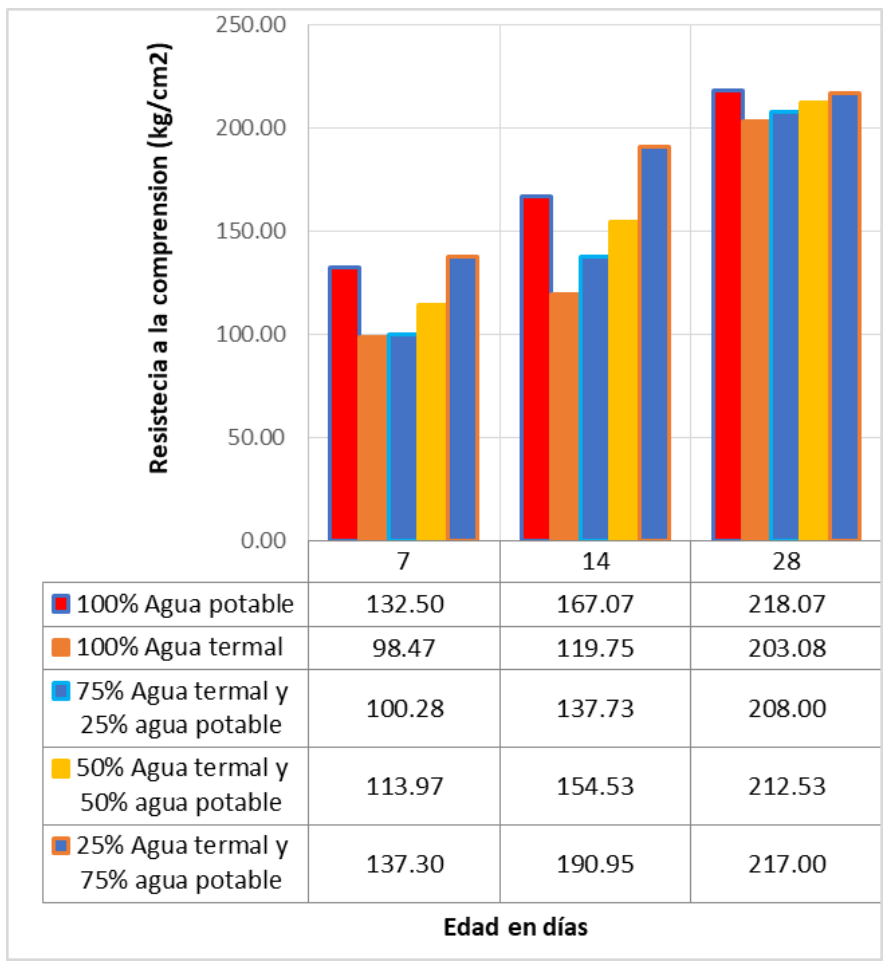

Figura 10. La resistencia a la compresión de todo las dosificaciones para los días 7, 14 y 28.

\section{Interpretación:}

En el gráfico se observa la tendencia de crecimiento en todas las curvas; sin embargo, para las diferentes concentraciones de agua termal se observa que la resistencia a compresión por debajo y arriba de la resistencia de la muestra de control elaborado con agua potable, pero si llegan todos al diseño que elaboramos que es de $F^{\prime} \mathrm{C}=210 \mathrm{~kg} / \mathrm{cm} 2$ vemos que todos llegan al diseño a los 28 días. También podemos observar que a los 14 días el $25 \%$ de agua termal tiene una tendencia muy elevada que el agua de control entonces presenta un incremento en la resistencia en más de $14 \%$ de resistencia esperada, observar en la figura $11 \mathrm{y}$ figura 12 .

En la tabla 5, a los 7 días de edad el concreto elaborado con agua potable tuvo una resistencia promedio de $105.12 \%$ con respecto al f'c de diseño, lo cual nos confirma que la reactividad del agua potable el concreto elaborado con $100 \%, 75 \%, 50 \%$, $25 \%$, de agua termal tuvo una resistencia promedio de $74.32 \%, \quad 75.68 \%, \quad 86.62 \%, \quad 103.62 \%$, respectivamente, se observa una variación y se debe a que el agua termal presentan contenidos de alcalinidad, calcio, bicarbonato y magnesio haciendo que la hidratación del cemento sea lenta en comparación con el agua potable. Pero el de 25
$\%$ de agua termal si cumple ya tiene menos porcentaje de los componentes de lagua termal.

En la tabla 6, a los 14 días de edad el concreto elaborado con agua potable tuvo una resistencia promedio de $99.44 \%$ con respecto al f'c de diseño, lo cual nos confirma que la reactividad del agua potable está en promedio, el concreto elaborado con $100 \%, 75 \%, 50 \%, 25 \%$, de agua termal tuvo una resistencia promedio de $71.67 \%, 82.43 \%, 92.49 \%$, $25 \%$, respectivamente, se observa variación esta se debe a que el agua termal presentan contenidos de alcalinidad, calcio, bicarbonato y magnesio haciendo que la hidratación del cemento sea lenta en comparación con el agua potable. Pero el de 25 $\%$ de agua termal tiene mejor resistencia que el agua potable ya que tiene en menor cantidad componentes del agua termal que mejora la hidratación del cemento.

En la tabla 7, a los 14 días de edad el concreto elaborado con agua potable tuvo una resistencia promedio de $103.84 \%$ con respecto al f'c de diseño, lo cual nos confirma que la reactividad del agua potable está en promedio, el concreto elaborado con $100 \% 75 \%, 50 \%$, 25\%, de agua termal tuvo una resistencia promedio de $93.13 \%, 95.38 \%, 97.46 \%$, $99.50 \%$, respectivamente, se observa que a la edad de 28 días el concreto elaborado con diferentes dosificaciones de agua termal tiene valores cercanos al concreto elaborado con agua potable y teniendo un promedio similar.

Por lo tanto, el concreto elaborado con agua termal del $100 \%, 75 \%$ y $50 \%$ la resistencia a la compresión a los 7 y 14 días es baja sobre control; pero a los 28 días si llega a la resistencia requerida, mientras el de $25 \%$ de agua termal a los 14 días la resistencia a compresión es mejor. También Chávez menciona "El porcentaje de variación de la resistencia a la edad de 180 días respecto a los 28 días de curado aumenta en un $0.4 \%$ cumpliendo con la durabilidad del concreto en el transcurso del tiempo tanto para el concreto de control como para el concreto elaborado con agua termal [5]".

\section{Conclusiones}

Se concluye que el impacto ambiental es positivo al usar el agua termal porque se toma un recurso dotado por la misma naturaleza y así evitar la degradación del ecosistema, disminuyendo el consumo masivo de agua potable para las mezclas de concreto en obras de infraestructura, haciendo que sean construcciones sostenibles sin afectar la 
resistencia, calidad, manejabilidad, fluencia, entre otros.

Se determinó la influencia de agua termal de $100 \%, 75 \%$, $50 \%$ y $25 \%$ en el peso unitario del concreto en estado fresco resultando 2146.21 $\mathrm{kg} / \mathrm{m} 3,2146.33 \mathrm{~kg} / \mathrm{m} 3,2146.86 \mathrm{~kg} / \mathrm{m} 3$ y 2147.34 $\mathrm{kg} / \mathrm{m} 3$ respectivamente el concreto elaborado con agua potable alcanzaron un valor de 2147.33 $\mathrm{kg} / \mathrm{m3}$, asimismo la influencia del agua termal en el peso unitario del concreto en estado endurecido están en el mismo rango los resultados; por lo tanto, el agua termal no tiene cambios relevantes en el peso unitario del concreto.

Los asentamientos obtenidos en las mezclas de concreto preparadas aguas termales de $100 \%, 75 \%, 50 \%$ y $25 \%$, teniendo resultados de 3.7 pulg, 3.6 pulg, 3.4 pulg y 3.3 pulg respectivamente y de agua potable es 3.1 pulg. de estos resultados podemos concluir que nuestras mezclas de concreto tienen consistencia normal y de buena manejabilidad, obteniendo resultados que a mayor dosificación de agua termal mayor asentamiento, observamos que los resultados si cumple con el diseño que fue de 3"- 4", lo que quiere decir que el agua termal influye significativamente en el asentamiento del concreto.

La resistencia a la compresión promedio a los 28 días del concreto de control es de $218.07 \mathrm{~kg} / \mathrm{cm} 2$ y del concreto con agua termal de $100 \%, 75 \%, 50 \%$ y $25 \%$ es de $203.08 \mathrm{~kg} / \mathrm{cm} 2,208 \mathrm{~kg} / \mathrm{cm} 2,212.53$ $\mathrm{kg} / \mathrm{cm} 2$ y $217 \mathrm{~kg} / \mathrm{cm} 2$ respectivamente están dentro de la resistencia requerida, con lo cual se concluye que el concreto cumple con la resistencia para la cual fue diseñado.

La resistencia a compresión en 14 días de $25 \%$ termal y $75 \%$ potable resulta más recomendables para su uso ya que se comprobó que tiene mayor resistencia a la compresión en más $10 \%$ de control o resistencia requerida, se recomienda el utilizar esta dosificación en lugares frígidos para evitar que se congele y causar retardo en el desarrollo de resistencias del concreto.

Si bien los ensayos superaron a tempranas edades y no superaron a los 28 días la resistencia de diseño, no se descarta que el concreto elaborado con agua termal reduzca su resistencia a través del tiempo debido a que el contenido de bicarbonato, calcio y alcalinidad en el agua termal en la mezcla; el diseño de mezcla no se elaboró teniendo en cuenta la resistencia por durabilidad.
Finalmente se concluye que es factible el uso del agua termal en la preparación del concreto puesto que cumple con los requisitos mínimos que señala la norma NTP 339 088, además la norma señala que se puede utilizar aguas no potables en el uso del concreto cuya reducción en sus propiedades del concreto no tenga variación significativa.

\section{Agradecimientos}

Al programa 066 de Vicerrectorado de investigación de la Universidad Nacional de Huancavelica, por el apoyo económico con el financiamiento del proyecto.

Al grupo de investigación "INTERFACULTATIVO SAECOZ" de la Universidad Nacional de Huancavelica, por su apoyo académico en la realización de este proyecto.

A la escuela profesional de ingeniería civil - Hvca de la Universidad Nacional de Huancavelica, por permitirnos hacer los ensayos en su laboratorio de tecnología de materiales y concreto de nuestro proyecto.

\section{Referencias}

[1] N. Nieto, "La gestión del agua: tensiones globales y latinoamericanas," Política y Cult., no. 36, pp. 157-176, 2011.

[2] G. Machacca and L. Aydee, "“ Efectos Sociales del Desabastecimiento en Agua Potable y Saneamiento Básico ,"' UTP Fac. Ing., vol. 0, no. 0, pp. 1-55, 2020.

[3] V. Vargas, "LAS FUENTES TERMALES EN EL PERU, ESTADO Y USO ACTUAL," Soc. Geológica del Perú, vol. 9, pp. 1175-1178, 2010.

[4] C. Condori and E. Guillen, "Contaminación De Las Aguas Termales De La Piscina Con Coliformes Fecales $Y$ Totales En Salud Pública El Barrio San Cristobal, Huancavelica-2016,"' 2018.

[5] M. Chavez Soto, "Resistencia a la compresión del concreto f'c $=210 \mathrm{~kg} / \mathrm{cm}^{2}$ utilizando agua termal, Cajamarca 2019," 2019.

[6] J. L. Cruzado Guevara and M. Li Zavaleta, "Análisis comparativo de la resistencia de un concreto convencional teniendo como variable el agua utilizada en el mezclado," Univ. Priv. Antenor Orrego, p. 98, 2016, [Online].

Available: https://repositorio.upao.edu.pe/handle/20.50 $0.12759 / 2038$.

[7] S. D. la C. J. A. Untiveros Leon Tobías 
Edverson, "Ingenioso investigador propone usar aguas termales en la producción de concreto | Noticias | Agencia Peruana de Noticias Andina," Agencia Peruana de Noticias Andina. https://andina.pe/agencia/noticia-ingeniosoinvestigador-propone-usar-aguas-termalesla-produccion-concreto-834870.aspx (accessed Nov. 16, 2021).

[8] F. Abanto Castillo, Tecnologia del Concreto (Teoria y problemas). 2009.

[9] R. P. Gotuzzo, "Elaboracion de diseño para contrastar hipotesis," 2018.

[10] NTP 334.009, "CEMENTOS. Cementos Portland. Requisitos," Indecopi, no. Lima 41, 2005.

[11] NTP 400.011, "Definicion y clasificacion de agregados para uso en morteros y hormigones (concreto )." 2013.

[12] NTP 400.037, "Agregados para concreto. Requisitos." 2018.

[13] NTP 339.070, "HORMIGÓN ( CONCRETO ). Toma de muestras de aguas usadas para la preparación y curado de morteros y concretos de cemento Portland y aguas agresivas." 2010.

[14] NTP 339.088, "HORMIGÓN (CONCRETO). Agua de mezcla utilizada en la producción del concreto de cemento portland. Requisitos." 2006.

[15] NTP 400.012, "AGREGADOS . Análisis granulométrico del agregado fino ," Norma Tecnica Peruana, no. Lima 41. p. 73, 2001.

[16] NTP.400.022, "Agregados. Método de ensayo normalizado para la densidad, densidad relativa(Peso específico) y absorción del agregado fino.," Norma Tec. Peru., 2013, [Online]. Available: https://www.studocu.com/pe/document/unive rsidad-privada-delnorte/ingenieria/372901324-ntp-400-0122013-pdf/5739579.
[17] ACl211, "Diseño de mezcla." 2009.

[18] NTP 339.033, "HORMIGÓN. Método de ensayo para elaboración y curado de probetas cilíndricas de concreto en obra." 1999.

[19] NTP 339.036, "CONCRETO. Práctica para muestreo de mezclas de concreto fresco," Inacal. 2017.

[20] NTP 334.077, "CEMENTOS. Ambientes, gabinetes y tanques de almacenamiento utilizados en los ensayos de cemento y concreto. Requisitos." 2007.

[21] NTP 339.034, "HORMIGÓN (CONCRETO). Método de ensayo normalizado para la determinación de la resistencia a la compresión del concreto en muestras cilíndricas," Indecopi, vol. 4, no. 3, p. 22, 2015, [Online]. Available: https://tiendavirtual.inacal.gob.pe/0/modulos/ TIE/TIE_DetallarProducto.aspx?PRO=4303.

[22] NTP 339.046, "Hormigón (concreto). Método de ensayo para determinar la densidad (peso unitario), rendimiento y contenido de aire (método gravimétrico) del hormigón (concreto)," Inacal, 2008.

[23] Ntp-339.035, "Método Para La Medición Del Asentamiento Del Concreto Con El Cono De Abrams," Indecopi, 1999, [Online]. Available: https://www.udocz.com/pe/read/26386/ntp339-035-1999-metodo-para-la-medicion-delasentamient-del-concreto-con-el-cono-deabrams- 1 .

E-mails de todos los autores untiverosleon@gmail.com jhonsver.shi@gmail.com danteoliver88@gmail.com 